\title{
Optimal Synthesis and Application of a Si-Ti-Al Ternary Alloy as an Anode Material for Lithium-Ion Batteries
}

\author{
Jaehan Lee ${ }^{1,+}$, Young-Min Kim ${ }^{2,+} \mathbb{D}$, Ju-Han Kim ${ }^{3,+}$, Jee-Woon Jeong ${ }^{4}$, Donghyun Lee ${ }^{5}$, Jae Wook Sung ${ }^{3}$, Young \\ Ju Ahn ${ }^{6}$, Jae-Hyun Shim ${ }^{4, *}$ and Sanghun Lee ${ }^{7, *}$
}

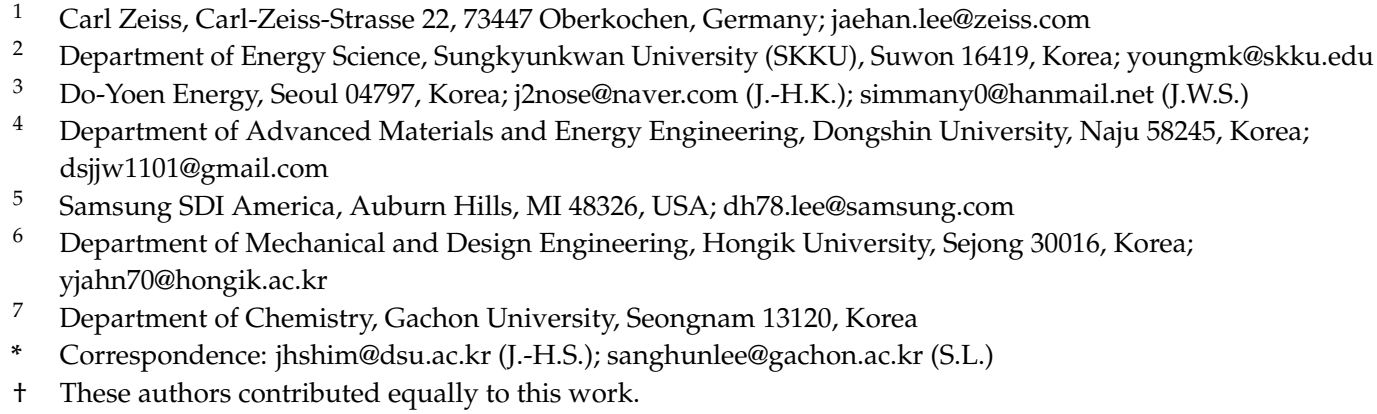

check for

updates

Citation: Lee, J.; Kim, Y.-M.; Kim, J.-H.; Jeong, J.-W.; Lee, D.; Sung, J.W.; Ahn, Y.J.; Shim, J.-H.; Lee, S. Optimal Synthesis and Application of a Si-Ti-Al Ternary Alloy as an Anode Material for Lithium-Ion Batteries. Materials 2021, 14, 6912. https:// doi.org/10.3390/ma14226912

Academic Editors: Yanan Chen and Junwei Wu

Received: 29 September 2021 Accepted: 14 November 2021 Published: 16 November 2021

Publisher's Note: MDPI stays neutral with regard to jurisdictional claims in published maps and institutional affiliations.

Copyright: (c) 2021 by the authors. Licensee MDPI, Basel, Switzerland. This article is an open access article distributed under the terms and conditions of the Creative Commons Attribution (CC BY) license (https:/ / creativecommons.org/licenses/by/ $4.0 /)$.

\begin{abstract}
The development of novel anode materials for high energy density is required. Alloying Si with other metals is a promising approach to utilize the high capacity of Si. In this work, we optimized the composition of a $\mathrm{Si}-\mathrm{Ti}-\mathrm{Al}$ ternary alloy to achieve excellent electrochemical performance in terms of capacity, cyclability, and rate capability. The detailed internal structures of the alloys were characterized through their atomic compositions and diffraction patterns. The lithiation process of the alloy was monitored using real-time scanning electron microscopy, revealing that the mechanical stability of the optimized alloy was strongly enhanced compared to that of the pure silicon material.
\end{abstract}

Keywords: lithium-ion battery; Si alloy; anode materials; real-time monitoring; lithiation

\section{Introduction}

Graphite has become valuable as an electrode material for lithium-ion batteries (LIB) in the past several decades. Graphite exhibits many excellent properties for use in LIB, such as high specific capacity, appropriate voltage, good rate capability, good thermal stability, low volume expansion during lithiation, and excellent electronic conductivity, while its low cost is one of its biggest advantages. Nevertheless, further improvements in the energy density of LIB have been pursued to meet the demands of applications such as electric vehicles and massive energy storage systems. Towards this goal, $\mathrm{Si}$ has received attention as a promising substitute for graphite [1]. Although the benefits of Si-anode materials are exaggerated because of their large specific capacities, Si remains a very good candidate in terms of the stack energy density, as proposed by Obrovac and Chevrier [2].

However, the repeated alloying/dealloying of Li into Si leads to unwanted volume changes, which cause significant capacity losses due to material pulverization. These problems hinder the commercial use of Si anodes in LIB. To address these issues, various nanostructural modifications such as nanoparticles [3-5], nanowires [6-8], nanotubes [9-11], and nanosheets $[12,13]$ have been developed for releasing large amounts of stress during cycling. The strategy of alloying Si with other elements has also been actively applied. As summarized in Obrovac and Chevrier's review [2], either active or inactive elements can be alloyed with $\mathrm{Si}$ to enhance the electrochemical performance of the anode material. When nanosized $\mathrm{Si}$ is present in a matrix of other active elements, such as $\mathrm{Sn}, \mathrm{Zn}$, and Al, the formation of the fully lithiated phase of $\mathrm{Si}\left(\mathrm{Li}_{15} \mathrm{Si}_{4}\right)$ is suppressed, leading to good cycling performance. Si-Al alloy, which is cheap and highly conductive, has been used not only 
as an active material [14-16] but also as a precursor to fabricate nanostructured $\mathrm{Si}$ with high porosity $[17,18]$. Meanwhile, alloying with inactive elements, such as $\mathrm{Fe}, \mathrm{Ni}, \mathrm{Co}$, and $\mathrm{Ti}$ (i.e., transition metal, TM) can reduce the overall alloy volume expansion, resulting in improved cycling performance. The inactive matrix phase buffers the volume expansion of the active Si phase and provides a continuous conduction pathway for electrons [19]. Fleischauer et al. proposed that the specific capacity of a particular Si-TM alloy can be predicted from the effective heat of formation [20]. Ti has been used as an alloy component with good electrochemical performance, and Si-Ti alloys have been manufactured using various methods [21-24]. Recently, Lee et al. reported that Ti is not simply inactive, but in fact binds to silicon atoms during lithiation [25].

Ternary alloys have also been developed to optimize the electrochemical performance of anodes. Fleischauer and Dahn investigated Si-Al-Mn alloys with over 200 compositions [26] using the combinatorial sputtering method to produce high-performance Si-alloy anodes $[27,28]$. However, their approach was a non-equilibrium process, which has technical limitations for practical applications on a large scale. Hence, alternative methods, such as spray-drying [29] or melt-spinning [30,31], have been proposed to improve the processability for industrial use. In particular, the melt-spinning method has been applied to other alloys for LIB anode materials [32,33]. In this work, a Si-Ti-Al ternary alloy prepared by melt-spinning was studied as an anode material for LIB. This ternary alloy system has hardly been studied as an anode material for LIB [21]. Here, a relatively uniform microstructure was obtained using arc-melting and spinning methods, which led to good electrochemical performance. To determine the optimal composition, a threecomponent $(\mathrm{Si}, \mathrm{Ti}$, and $\mathrm{Al}$ ) phase diagram was used [34]. The structure of the $\mathrm{Si}$ alloy with good cycling ability was determined, and the suppression of the volume expansion was visually confirmed.

\section{Experimental Section}

Si alloys for the anode were prepared by mixing $\mathrm{Si}$ (99.999\% purity), $\mathrm{Ti}$ (99.9\% purity), and $\mathrm{Al}$ (99.9\% purity) in the molar ratios listed in Table 1 . All alloys were prepared under an Ar atmosphere using an arc-melting process [30]. In all three compositions, the weight of $\mathrm{Si}$ was fixed at $50 \%$, and only the ratios of titanium and aluminum were adjusted. The theoretical capacities of the samples, which are estimated by the lever rule using the phase diagram [35], are listed in Table 1.

Table 1. $\mathrm{Si}, \mathrm{Al}$, and Ti molar ratios for the ternary alloys and their theoretical capacities.

\begin{tabular}{ccccc}
\hline Sample & $\mathbf{S i}$ & $\mathbf{T i}$ & $\mathbf{A l}$ & Theoretical Capacity (mAh/g) \\
\hline STA1 & 0.50 & 0.15 & 0.35 & 1111.1 \\
STA2 & 0.50 & 0.10 & 0.40 & 1366.4 \\
STA3 & 0.50 & 0.05 & 0.45 & 1650.6 \\
\hline
\end{tabular}

The alloys were fabricated into ribbons using the melt-spinning method. The alloys were heated inside a graphite nozzle by a high-frequency induction current in an Ar atmosphere. This kept the alloys in the melt phase while they were squeezed out through a slit onto a rotating copper wheel $(1400 \mathrm{rpm})$, where they were rapidly cooled. The average thickness of the alloy ribbons was $\sim 35 \mu \mathrm{m}$. The cooling was very fast; consequently, the nucleation was faster than the crystal growth, resulting in very fine structures. Alloy powders were obtained by grinding $10 \mathrm{~g}$ of the alloy with $600 \mathrm{~g}$ of zirconia ( $5 \mathrm{~mm}$ diameter). A schematic of the Si-alloy fabrication process is shown in Figure 1. 

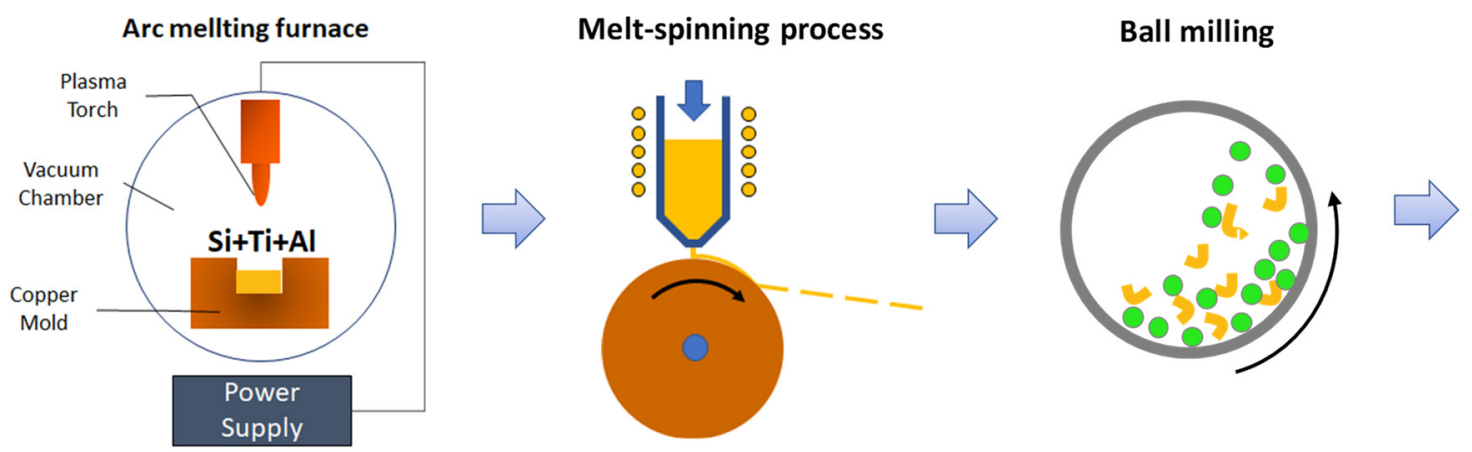

\section{Si alloy particles}

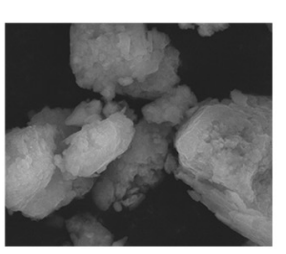

Figure 1. Schematic of the Si-alloy fabrication process.

The negative electrode slurry was prepared by mixing the alloy powders, Ketjen black (Lion, Tokyo, Japan), and polyimide binder (Kureha, Tokyo, Japan) with a weight ratio of 86.6:3.4:10 in N-methylpyrrolidone. The solvent was dried at $80{ }^{\circ} \mathrm{C}$ in a convection oven (JEIO TECH, Daejeon, Korea) for $2 \mathrm{~h}$, and then the binder was cured at $350{ }^{\circ} \mathrm{C}$ in a hydrogen atmosphere for $2 \mathrm{~h}$. Following this, 2032 coin half cells were fabricated using Li metal (anode), silicon alloy (cathode), $1 \mathrm{M} \mathrm{LiPF}_{6}$ in ethylene carbonate and diethyl carbonate with a volume ratio of 3:7 (electrolyte, Solbrain, Kongju, Korea), and a polypropylene separator (Enerever, Suwon, Korea). The electrochemical characteristics of the coin cells were analyzed in the operating voltage range of $0-2 \mathrm{~V}$ in constant current $(\mathrm{CC})$ and constant voltage $(\mathrm{CV})$ modes with rates of $0.1 \mathrm{C}$ and $0.05 \mathrm{C}$, respectively. The discharging rate was $0.1 \mathrm{C}$.

The crystal structures of the silicon alloys were examined using $\mathrm{X}$-ray diffraction (XRD) at ambient temperature (Rigaku MiniFlex 600, Rigaku Corporation, Tokyo, Japan) using filtered $\mathrm{Cu}-\mathrm{K} \alpha$ radiation $(\lambda=1.54056 \AA)$. The surface morphologies of the alloys were observed using field-emission scanning electron microscopy (FE-SEM; SU500, Hitachi, Tokyo, Japan). Atomic resolution images were taken using a $200 \mathrm{kV}$ aberration-corrected scanning transmission electron microscope (JEM-ARM200CF, Jeol Ltd., Tokyo, Japan). The detector angle ranges for the high-angle annular dark-field (HAADF) and annular bright-field (ABF) imaging modes were 70-175 and 7.5-17 mrad, respectively. Elemental distribution maps of the samples were acquired using scanning transmission electron microscopy (STEM) along with energy dispersive X-ray spectroscopy (EDX) (JED-2300T, Jeol Ltd., Tokyo, Japan) that was equipped with a dual-type detector having a large effective solid angle ( 1.2 sr). The electron probe size was $\sim 1.1 \AA$. Cross-sectional transmission electron microscopy (TEM) and selected area electron diffraction (SAED) were performed. The samples were prepared using a focused ion beam (FIB, Auriga CrossBeam Workstation, Carl Zeiss, Oberkochen, Germany).

We combined a scanning electron microscope (GeminiSEM 300, Carl Zeiss, Oberkochen, Germany) with a charging circuit to visually observe the lithiation process of the alloys. One microprobe (MM3A-EM, Kleindiek, Reutlingen, Germany) was placed on a Si alloy particle inside the SEM, while the other probe was connected to the lithium metal. Then, a current of $10 \mu \mathrm{A}$ was supplied between the probes for $1 \mathrm{~h}$ to lithiate the Si alloy. During lithiation, changes in the Si alloy particles and lithium metal were monitored using SEM.

\section{Results and Discussion}

Figure 2 displays SEM images of the anode particles. All three materials consisted of irregular particles, $10-20 \mu \mathrm{m}$ in size, with rough surfaces; there was no apparent dependence of the outer appearance on the alloy atomic ratio. The XRD patterns of the three materials are shown in Figure 3. All three materials contained $\mathrm{Si}, \mathrm{Al}$, and $\mathrm{TiAl}_{3}$ phases. STA1 had both $\mathrm{TiSi}_{2}$ and $\mathrm{Ti}_{2} \mathrm{AlSi}_{3}$ phases, while STA2 had only $\mathrm{Ti}_{2} \mathrm{AlSi}_{3}$ due to its higher $\mathrm{Al}$ content. However, STA3 had neither $\mathrm{TiSi}_{2}$ nor $\mathrm{Ti}_{2} \mathrm{AlSi}_{3}$, that is, a crystalline phase containing both Ti and Si was not formed in STA3. 


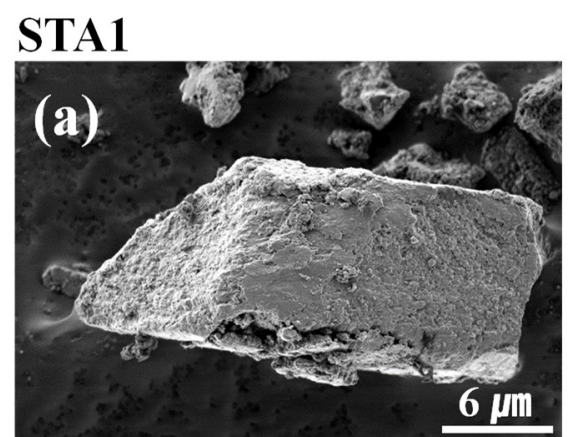

STA2

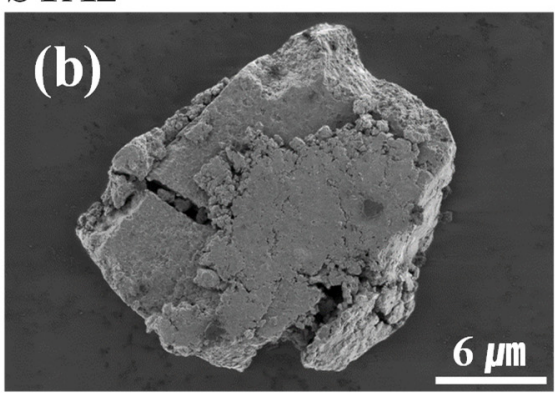

STA3
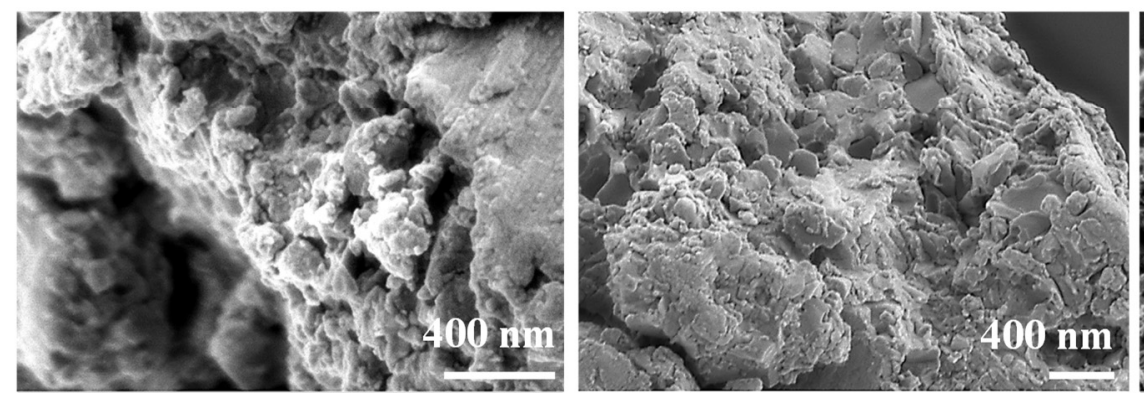

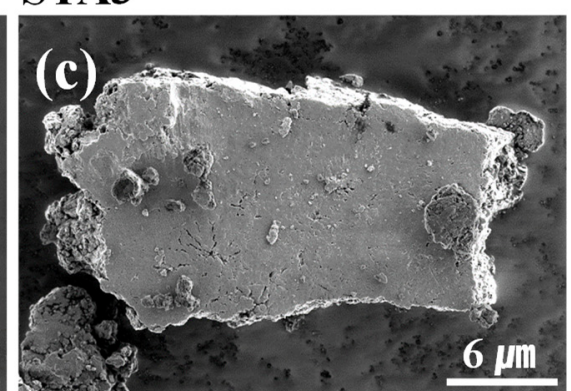

Figure 2. SEM images of (a) STA1, (b) STA2, and (c) STA3.

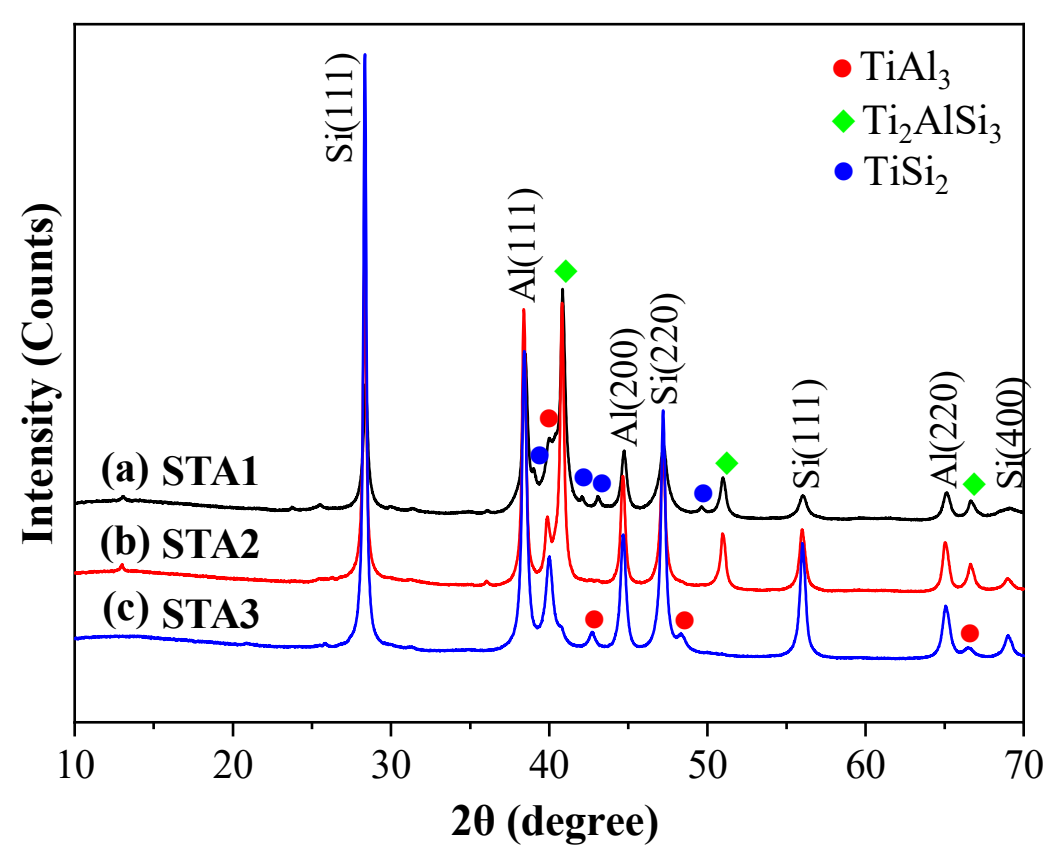

Figure 3. XRD patterns of (a) STA1, (b) STA2, and (c) STA3.

The particle cross-sections were then investigated using STEM with EDX. As shown in Figure 4, STA1 had a significant amount of a Ti-Si composite phase (yellow color in Figure 4 b), whereas STA3 had only a small amount. Ti (green color in Figure $4 n$ ) was rarely observed in STA3. In STA2, the Si-only phase (red color in Figure 4h) appeared to be richer than that in STA1, which may be related to the higher theoretical capacity of STA2. The SAED patterns (Figure $4 \mathrm{f}, \mathrm{l}, \mathrm{r}$ ) also confirmed the crystalline phases of the respective materials, which were consistent with the XRD results. Figure S1 (supplementary information) shows the internal structure of STA2 as determined from STEM measurements. 

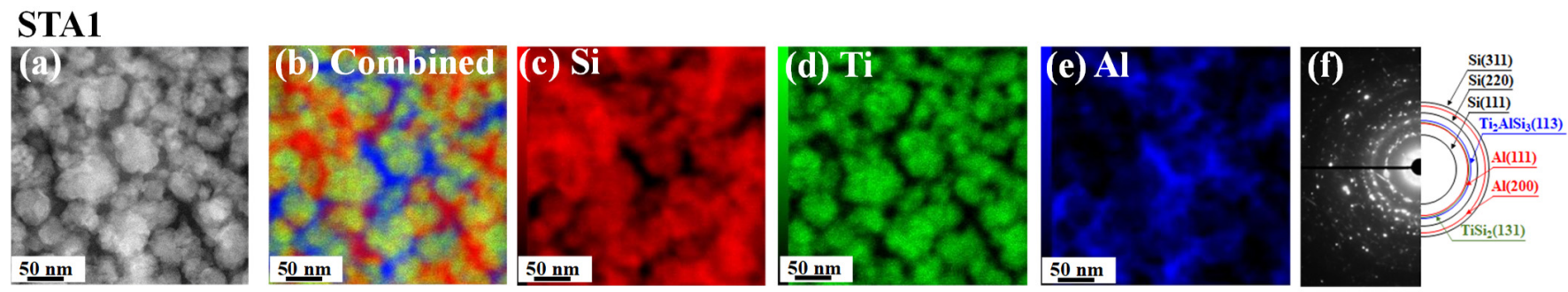

\section{STA2}
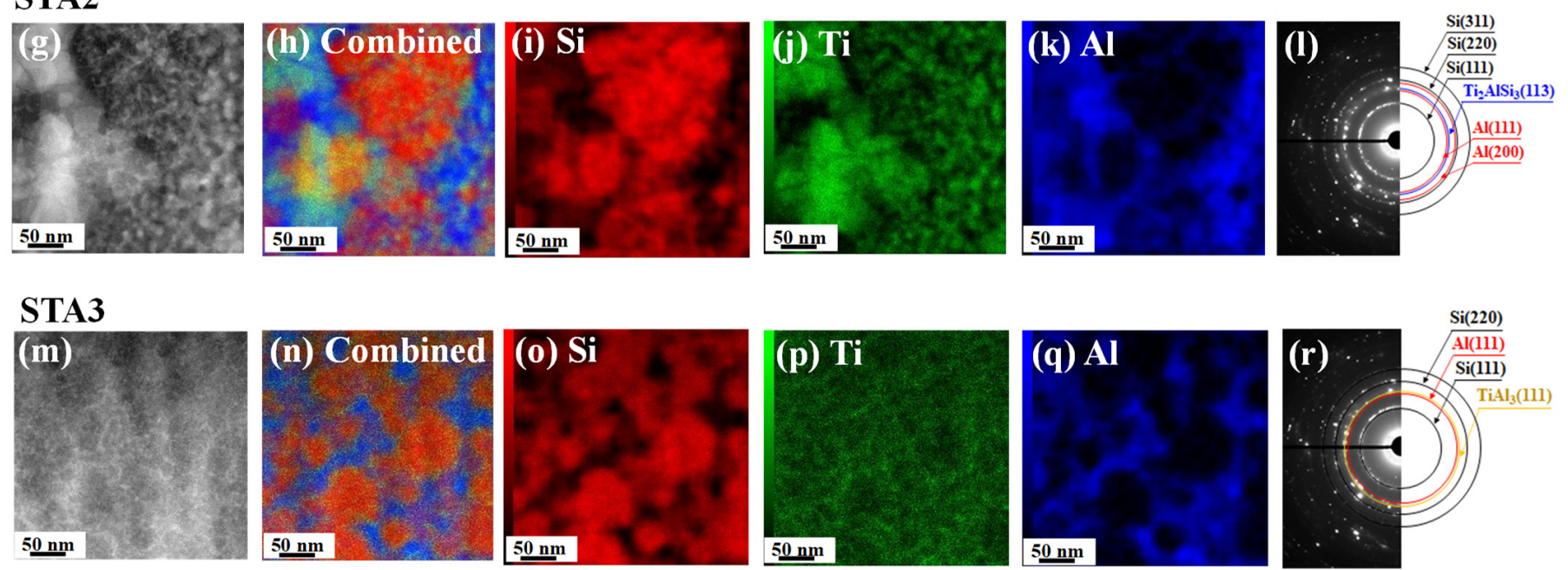

Figure 4. STEM images (a,g,m), EDX images $(\mathbf{b}-\mathbf{e}, \mathbf{h}-\mathbf{k}, \mathbf{n}-\mathbf{n}-\mathbf{q})$, and SAED patterns $(\mathbf{f}, \mathbf{l}, \mathbf{r})$ of STA1, STA2, and STA3.

Figure 5 shows the cycling performance and incremental discharge rate capability of the samples in a coin cell assembly. The cycling properties in the voltage range from 0.01 to $2.0 \mathrm{~V}$ were determined using a discharge rate of $0.1 \mathrm{C}$. Increasing the Al content (decreasing the Ti content) resulted in a significant increase in the initial capacity. The crystalline phases of $\mathrm{Ti}$ and $\mathrm{Si}$, such as $\mathrm{TiSi}_{2}$, are not active in electrochemical lithiation [36]. Hence, STA3, which contains the most Si-only phase, had the highest capacity. However, STA3 exhibited a significant capacity decline in the early cycles owing to the lack of $\mathrm{TiSi}_{2}$ or $\mathrm{Ti}_{2} \mathrm{AlSi}_{3}$, which plays a role in charge transport as well as structural support [36]. Meanwhile, STA2, which showed an initial capacity of $\sim 1400 \mathrm{mAh} / \mathrm{g}$, maintained a high capacity of $\sim 890 \mathrm{mAh} / \mathrm{g}$ after 50 cycles. The high initial capacity of STA3 at $0.05 \mathrm{C}$ rapidly declined as the discharge rate increased, and at 5.0 C, it became almost the same as that of STA2. Thus, the electrochemical performance evaluation indicates that STA2 has an optimal composition as an anode material for LIB. The capacity retention and Coulombic efficiency of the samples were also consistent with this evaluation (Figure S2 in the supplementary information).

SEM combined with a charge/discharge circuit was used to visually confirm the durability of the alloy system in situ during lithiation. Figure 6 displays frames from a video of the lithiation processes in the STA2 sample. Li atoms in contact with the active material of STA2 penetrated the bulk of STA2 (circle in Figure 6b); however, no noticeable changes such as crack formation or expansion were observed in the alloy active material. Compared to pure silicon active material, where large cracks develop as lithiation progresses (Figure S3 in the supplementary information), it is apparent that STA2 had high durability throughout the lithiation process. Movies of the lithiation processes of STA2 and pure $\mathrm{Si}$, from which the images in Figure 6 and Figure S3 were taken, are provided in the supplementary information. 

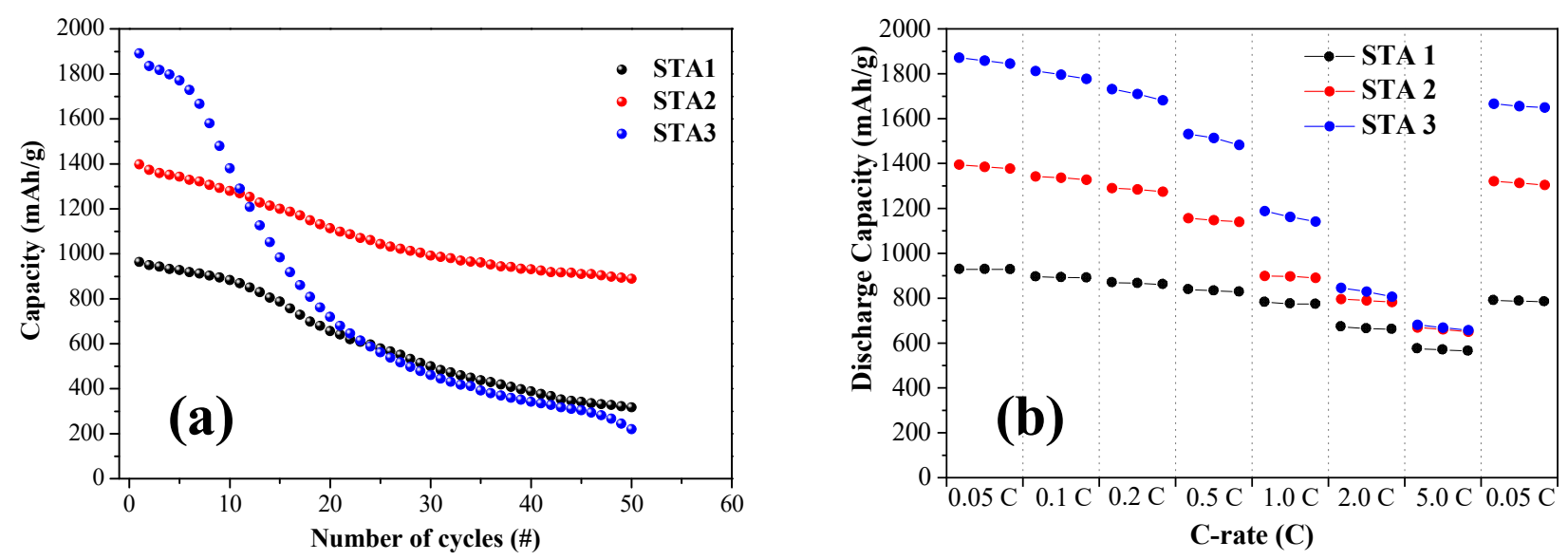

Figure 5. (a) Discharge capacity vs. cycle and (b) rate capability of STA1, STA2, and STA3.

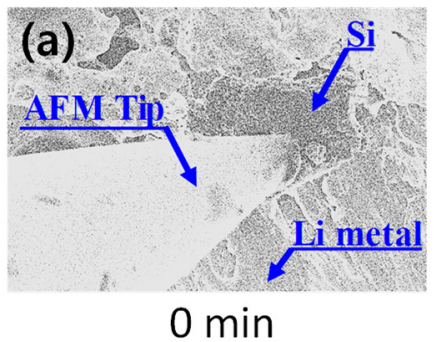

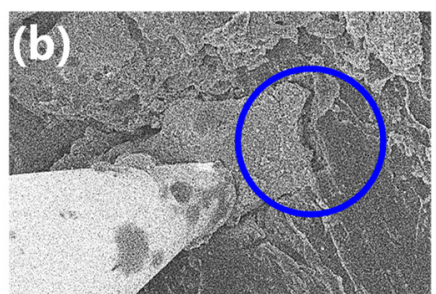

$3.5 \mathrm{~min}$

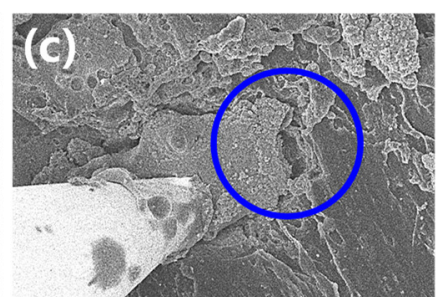

$18.5 \mathrm{~min}$

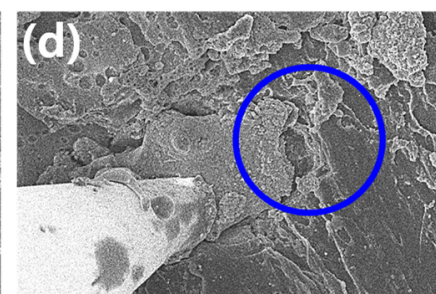

$30.5 \mathrm{~min}$

Figure 6. SEM images of the lithiation process in STA2. (a) $0 \mathrm{~min}$, (b) $3.5 \mathrm{~min}$, (c) $18.5 \mathrm{~min}$, and (d) $30.5 \mathrm{~min}$.

In accordance with the above results, an effective anode material requires both $\mathrm{Si}-\mathrm{Ti}-$ $\mathrm{Al}$ and Si-only phases for durability and capacity, respectively. When the amount of Ti is too large (STA1), the Si-only phase is not sufficiently formed; thus, the capacity of the material is reduced. On the contrary, when Ti is insufficient (STA3), the mechanical stability of the material is not guaranteed. Although this work provides a practical guideline for optimizing the composition of the $\mathrm{Si}-\mathrm{Ti}-\mathrm{Al}$ ternary alloy, there remains a future task to develop a more precise and systematic approach to achieve the optimal composition.

\section{Conclusions}

We demonstrated $\mathrm{Si}-\mathrm{Ti}-\mathrm{Al}$ ternary alloys as high-performance negative electrodes for lithium-ion batteries. The relatively uniform microstructure of the alloys was accomplished by an arc-melting and spinning process. The optimized composition for the best electrochemical performance, STA2, contains both the $\mathrm{Ti}_{2} \mathrm{AlSi}_{3}$ phase, which plays a role in charge transport and stability, and the Si-only phase, which is responsible for the high capacity. The excellent mechanical robustness of STA2 against lithiation during electrochemical charging was visualized in situ using SEM. No significant damage during the charging process, such as cracks or splits, was observed, which indicates a significant improvement in the mechanical characteristics of the $\mathrm{Si}$ anode materials.

Supplementary Materials: The following are available online at https:/ / www.mdpi.com/article/ 10.3390/ma14226912/s1, Figure S1: Atom-resolved high angle annular dark field (HAADF)-STEM images for (a) Ti2AlSi3 and (b) Si of STA2. The corresponding fast Fourier transform diffraction pattern is also shown at the right bottom of each image, Figure S2: Capacity retention and Coulombic efficiency of STA1, STA2, and STA3, Figure S3: SEM images of the lithiation process.

Author Contributions: Data curation, D.L.; Formal analysis, J.-W.J.; Investigation, Y.-M.K. and J.H.K.; Methodology, J.W.S. and J.-H.S.; Supervision, J.-H.S. and S.L.; Writing-original draft, J.L.; Writing-review \& editing, Y.J.A., J.-H.S. and S.L. All authors have read and agreed to the published version of the manuscript. 
Funding: This work was supported by grants from the National Research Foundation (NRF) of Korea (NRF-2021R1A2C101108011 and NRF-2020R1I1A3074134) and Jeollanam-do (2020 R\&D supporting program), by the Korea Basic Science Institute (National Research Facilities and Equipment Center) grant funded by the Ministry of Education (2020R1A6C101A184) and the Regional Innovation Strategy (RIS) program through the NRF funded by the Ministry of Education (MOE-1345341782).

Institutional Review Board Statement: Not applicable.

Informed Consent Statement: Not applicable.

Data Availability Statement: The data presented in this study are available upon request from the corresponding author.

Conflicts of Interest: The authors declare no conflict of interest.

\section{References}

1. Zuo, X.; Zhu, J.; Müller-Buschbaum, P.; Cheng, Y.-J. Silicon based lithium-ion battery anodes: A chronicle perspective review. Nano Energy 2017, 31, 113-143. [CrossRef]

2. Obrovac, M.N.; Chevrier, V.L. Alloy Negative Electrodes for Li-Ion Batteries. Chem. Rev. 2014, 114, 11444-11502. [CrossRef] [PubMed]

3. Rahman, A.; Song, G.; Bhatt, A.I.; Wong, Y.C.; Wen, C. Nanostructured Silicon Anodes for High-Performance Lithium-Ion Batteries. Adv. Funct. Mater. 2016, 26, 647-678. [CrossRef]

4. Wen, Y.; Zhu, Y.; Langrock, A.; Manivannan, A.; Ehrman, S.H.; Wang, C. Graphene-Bonded and -Encapsulated Si Nanoparticles for Lithium Ion Battery Anodes. Small 2013, 9, 2810-2816. [CrossRef]

5. Hwang, T.H.; Lee, Y.M.; Kong, B.-S.; Seo, J.-S.; Choi, J.W. Electrospun Core-Shell Fibers for Robust Silicon Nanoparticle-Based Lithium Ion Battery Anodes. Nano Lett. 2012, 12, 802-807. [CrossRef]

6. Liu, N.; Hu, L.; McDowell, M.T.; Jackson, A.; Cui, Y. Prelithiated Silicon Nanowires as an Anode for Lithium Ion Batteries. ACS Nano 2011, 5, 6487-6493. [CrossRef]

7. Xu, W.; Vegunta, S.S.S.; Flake, J.C. Surface-modified silicon nanowire anodes for lithium-ion batteries. J. Power Sources 2011, 196, 8583-8589. [CrossRef]

8. Chen, H.; Xiao, Y.; Wang, L.; Yang, Y. Silicon nanowires coated with copper layer as anode materials for lithium-ion batteries. J. Power Sources 2011, 196, 6657-6662. [CrossRef]

9. Wen, Z.; Lu, G.; Mao, S.; Kim, H.; Cui, S.; Yu, K.; Huang, X.; Hurley, P.T.; Mao, O.; Chen, J. Silicon nanotube anode for lithium-ion bat-teries. Electrochem. Commun. 2013, 29, 67-70. [CrossRef]

10. Song, T.; Xia, J.; Lee, J.-H.; Lee, D.H.; Kwon, M.-S.; Choi, J.-M.; Wu, J.; Doo, S.K.; Chang, H.; Park, W.I.; et al. Arrays of Sealed Silicon Nanotubes As Anodes for Lithium Ion Batteries. Nano Lett. 2010, 10, 1710-1716. [CrossRef]

11. Wu, H.; Chan, G.; Choi, J.W.; Ryu, I.; Yao, Y.; McDowell, M.T.; Lee, S.W.; Jackson, A.; Yang, Y.; Hu, L.; et al. Stable cycling of double-walled silicon nanotube battery anodes through solid-electrolyte interphase control. Nat. Nanotechnol. 2012, 7, 310-315. [CrossRef] [PubMed]

12. Chen, S.; Chen, Z.; Xu, X.; Cao, C.; Xia, M.; Luo, Y. Scalable 2D mesoporous silicon nanosheets for high-performance lithium-ion battery anode. Small 2018, 14, 1703361. [CrossRef] [PubMed]

13. Kim, W.-S.; Hwa, Y.; Shin, J.-H.; Yang, M.; Sohn, H.-J.; Hong, S.-H. Scalable synthesis of silicon nanosheets from sand as an anode for Li-ion batteries. Nanoscale 2014, 6, 4297-4302. [CrossRef] [PubMed]

14. Fleischauer, M.D.; Obrovac, M.N.; Dahn, J.R. Al-Si Thin-Film Negative Electrodes for Li-Ion Batteries. J. Electrochem. Soc. 2008, 155, A851-A854. [CrossRef]

15. Tahmasebi, M.H.; Kramer, D.; Geßwein, H.; Zheng, T.; Leung, K.-C.; Lo, B.T.W.; Mönig, R.; Boles, S.T. In situ formation of alumi-num-silicon-lithium active materials in aluminum matrices for lithium-ion batteries. J. Mater. Chem. A 2020, 8, 4877-4888. [CrossRef]

16. Chen, Z.; Hou, J.; Liu, Q.; Zhou, Q.; Liu, H.; Xu, C. Graphene quantum dots modified nanoporous SiAl composite as an advanced anode for lithium storage. Electrochim. Acta 2019, 318, 228-235. [CrossRef]

17. Hwang, G.; Park, H.; Bok, T.; Choi, S.; Lee, S.; Hwang, I.; Choi, N.-S.; Seo, K.; Park, S. A high-performance nanoporous Si/Al2O3 foam lithium-ion battery anode fabricated by selective chemical etching of the Al-Si alloy and subsequent thermal oxidation. Chem. Commun. 2015, 51, 4429-4432. [CrossRef]

18. Su, J.; Zhang, C.; Chen, X.; Liu, S.; Huang, T.; Yu, A. Carbon-shell-constrained silicon cluster derived from Al-Si alloy as long-cycling life lithium ion batteries anode. J. Power Sources 2018, 381, 66-71. [CrossRef]

19. Kim, S.-H.; Lee, D.H.; Park, C.; Kim, D.-W. Nanocrystalline silicon embedded in an alloy matrix as an anode material for high energy density lithium-ion batteries. J. Power Sources 2018, 395, 328-335. [CrossRef]

20. Fleischauer, M.D.; Mar, R.; Dahn, J.R. Method to predict phase formation and specific capacity for lithium in codeposited sili-con-transition metal thin films. J. Electrochem. Soc. 2007, 154, A151-A155. [CrossRef]

21. Lee, K.-M.; Lee, Y.-S.; Kim, Y.-W.; Sun, Y.-K.; Lee, S.-M. Electrochemical characterization of Ti-Si and Ti-Si-Al alloy anodes for Li-ion batteries produced by mechanical ball milling. J. Alloys Compd. 2009, 472, 461-465. [CrossRef] 
22. Kim, Y.M.; Ahn, J.; Yu, S.-H.; Chung, D.Y.; Lee, K.J.; Lee, J.-K.; Sung, Y.-E. Titanium Silicide Coated Porous Silicon Nanospheres as Anode Materials for Lithium Ion Batteries. Electrochim. Acta 2015, 151, 256-262. [CrossRef]

23. Wang, X.; Wen, Z.; Liu, Y.; Huang, L.; Wu, M. Study on Si-Ti alloy dispersed in a glassy matrix as an anode material for lithium-ion batteries. J. Alloys Compd. 2010, 506, 317-322. [CrossRef]

24. Zhou, Z.; Dong, P.; Wang, D.; Liu, M.; Duan, J.; Nayaka, G.; Wang, D.; Xu, C.; Hua, Y.; Zhang, Y. Silicon-titanium nanocomposite synthesized via the direct electrolysis of $\mathrm{SiO} 2 / \mathrm{TiO} 2$ precursor in molten salt and their performance as the anode material for lithium ion batteries. J. Alloys Compd. 2019, 781, 362-370. [CrossRef]

25. Lee, P.-K.; Tahmasebi, M.H.; Ran, S.; Boles, S.T.; Yu, D.Y.W. Leveraging Titanium to Enable Silicon Anodes in Lithium-Ion Batteries. Small 2018, 14, e1802051. [CrossRef]

26. Fleischauer, M.D.; Dahn, J.R. Combinatorial Investigations of the Si-Al-Mn System for Li-Ion Battery Applications. J. Electrochem. Soc. 2004, 151, A1216-A1221. [CrossRef]

27. Fleischauer, M.D.; Obrovac, M.N.; Dahn, J.R. Simple model for the capacity of amorphous silicon-aluminium-transition metal negative electrode materials. J. Electrochem. Soc. 2006, 153, A1201-A1205. [CrossRef]

28. MacEachern, L.; Dunlap, R.A.; Obrovac, M.N. A Combinatorial Investigation of Fe-Si-Zn Thin Film Negative Electrodes for Li-Ion Batteries. J. Electrochem. Soc. 2014, 162, A229-A234. [CrossRef]

29. Chae, S.; Ko, M.; Park, S.; Kim, N.; Ma, J.; Cho, J. Micron-sized Fe-Cu-Si ternary composite anodes for high energy Li-ion batteries. Energy Environ. Sci. 2016, 9, 1251-1257. [CrossRef]

30. Umirov, N.; Seo, D.-H.; Kim, H.-Y.; Kim, S.-S. Pragmatic Approach to Design Silicon Alloy Anode by the Equilibrium Method. ACS Appl. Mater. Interfaces 2020, 12, 17406-17414. [CrossRef]

31. Suh, S.-S.; Yoon, W.Y.; Lee, C.-G.; Kwon, S.-U.; Kim, J.-H.; Matulevich, Y.; Kim, Y.-U.; Park, Y.; Jeong, C.-U.; Chan, Y.-Y.; et al. Implementation and Characterization of Silicon Anode with Metal Alloy Inactive Matrix for Lithium-Ion Secondary Batteries. J. Electrochem. Soc. 2013, 160, A751-A755. [CrossRef]

32. Jingling, M.; Fengzhang, R.; Guangxin, W.; Yi, X.; Yaqiong, L.; Jiuba, W. Electrochemical performance of melt-spinning Al-Mg-Sn based anode alloys. Int. J. Hydrogen Energy 2017, 42, 11654-11661. [CrossRef]

33. Srinivas, M.; Kumar, A.S.; Majumdar, B.; Neelakantan, L. Enhanced capacity of SnCoC anode by melt spinning and ball milling for Li-ion battery. Mater. Today Commun. 2017, 13, 53-56. [CrossRef]

34. Azevedo, C.D.F.; Flower, H. Calculated ternary diagram of Ti-Al-Si system. Mater. Sci. Technol. 2000, 16, 372-381. [CrossRef]

35. Kim, J.S.; Umirov, N.; Kim, H.-Y.; Kim, S.-S. Fundamental Approach to Capacity Prediction of Si-Alloys as Anode Material for Li-ion Batteries. J. Electrochem. Sci. Technol. 2018, 9, 51-59. [CrossRef]

36. Zhou, S.; Liu, X.; Wang, D. Si/TiSi 2 Heteronanostructures as High-Capacity Anode Material for Li Ion Batteries. Nano Lett. 2010, 10, 860-863. [CrossRef] 